\title{
Effect of diet on growth, survival and fatty acid profile of marine amphipods: implications for utilisation as a feed ingredient for sustainable aquaculture
}

\author{
Hilke Alberts-Hubatsch ${ }^{1, *}$, Matthew James Slater ${ }^{1}$, Jan Beermann ${ }^{1,2}$ \\ ${ }^{1}$ Alfred Wegener Institute, Helmholtz Centre for Polar and Marine Research, 27570 Bremerhaven, Germany \\ ${ }^{2}$ Helmholtz Institute for Functional Marine Biodiversity, 26129 Oldenburg, Germany
}

\begin{abstract}
Rapidly expanding fed aquaculture demands high-quality, sustainable nutrient sources for utilisation as dietary ingredients. Exploring the potential of under-utilised resources from other industries is imperative to replace finite natural resources, such as fish meal. Marine gammarids may be an excellent source of essential fatty acids; however, their aquaculture using formulated diets remains untested in terms of survival, growth and nutritional value of the cultured product. Here, juveniles of 2 marine gammarid species, Gammarus locusta and Echinogammarus marinus, were maintained in controlled feeding experiments with 2 marine diets (Ulva spp. and Fucus spp.) and 2 terrestrial diets (lupin meal and carrot leaves). G. locusta exhibited higher survival rates, particularly when fed carrot leaves, an agricultural waste product. Fatty acid profiles of the resulting G. locusta product appear well suited for marine finfish nutrition, indicating high suitability of $G$. locusta as an aquaculture diet source. In contrast, whilst $E$. marinus may provide beneficial fatty acid profiles for aquatic animal nutrition, its poor growth performance in this study indicates that further dietary/culture research is required for this species. Our results indicate, for the first time, that marine gammarids are capable of trophic upgrading and can use nonmarine diets for healthy growth in culture, but their suitability as a formulated feed ingredient for specific fish or crustacean species needs to be investigated individually. Future research should include the development of optimal large-scale production as well as investigation of optimal methods of inclusion of gammarids as feed ingredient for target aquaculture species.
\end{abstract}

KEY WORDS: Essential fatty acid $\cdot$ Nutrition $\cdot$ Trophic upgrading $\cdot$ Terrestrial feeds $\cdot$ Gammarids

\section{INTRODUCTION}

The extraordinary growth of global aquaculture creates new challenges to sustainably meet feed supply needs, in particular to replace supply-limited fish meal and fish oil (FAO 2018). Fish meal and oil are essential nutritional feed sources in most aquafeeds, as they provide long-chain poly-unsaturated fatty acids (LC-PUFAs), which are pivotal for healthy development in many aquatic organisms (Glencross 2009, Parrish 2009). LC-PUFAs are unsaturated fatty acids (FAs) consisting of 20 carbons $\left(\mathrm{C}_{20^{-}}\right)$or more

*Corresponding author: halberts@awi.de
(Glencross 2009, Naylor et al. 2009) and are of marine origin. It was long assumed that LC-PUFAs were produced solely by primary producers, and only recently was first evidence provided that some higher aquatic invertebrates feature genes for de novo synthesis of PUFAs (Brett \& Muller-Navarra 1997, Monroig et al. 2013, Kabeya et al. 2018).

Despite efforts to replace fishmeal and oil in aquafeeds with alternative and more sustainable protein and lipid sources (e.g. plant proteins; Floreto et al. 2000, Barlow et al. 2003), reliance on LCPUFAs from fish oils remains a significant bottle-

() The authors 2019. Open Access under Creative Commons by Attribution Licence. Use, distribution and reproduction are unrestricted. Authors and original publication must be credited. 
neck in fish nutrition. Alternative production of LCPUFAs exists through bio-engineering by genetic modification of higher plants or microorganisms, enhancement of microalgae and the substitution of fishmeal by alternative under-utilised marine sources such as krill meal (e.g. Naylor et al. 2009, Nichols et al. 2010). However, these alternatives are either expensive, their commercial production is not permitted, or the sustainability issue is simply rerouted by the exploitation of other limited natural resources. Culturing emerging species for novel highvalue feed ingredients can reduce the environmental impact of feed production by taking pressure off natural resources.

Amphipod crustaceans constitute a significant part of benthic communities in terms of diversity, abundance and biomass in nearly all aquatic habitats worldwide (e.g. Odum \& Heald 1972, Dauby et al. 2001, Väinölä et al. 2008, Tempestini et al. 2018). Amphipods are important food items for many demersal fish and invertebrate species (Wakabara et al. 1982, Lagardère 1987, Edgar 1990, Amara et al. 2001, Pita et al. 2002). Accordingly, they exhibit an adequate nutritional profile as fish diets and are of increasing interest in recent research in the field of aquatic animal nutrition (Woods 2009, Baeza-Rojano et al. 2010, 2014, Guerra-García et al. 2016). Previous studies have shown that selected marine species are high in LC-PUFAs and exhibit high potential as aquaculture diets (Baeza-Rojano et al. 2014, Khodadadnia et al. 2016, Jiménez-Prada et al. 2018).

Many gammarid species can be maintained in laboratory cultures (Sexton 1928, Costa \& Costa 2000, Hughes \& Ahyong 2016). However, there is a dearth of research on the potential of gammarids as a novel aquatic crop to be produced in commercial-scale feed systems to provide high-value LC-PUFAs. To date, the effect of formulated or waste diets on the nutritional profile of gammarids is still unknown, and information on larger-scale production of marine gammarid biomass for industrial diet applications is missing.

This study assessed different feed sources for the rearing of marine amphipods and the potential of the resulting gammarids for aquaculture diet applications. The sympatric species Echinogammarus marinus (Leach 1815) and Gammarus locusta (Linnaeus 1758) were tested ${ }_{i}$ these 2 species from the North Sea can be cultured at laboratory scale (Beermann et al. 2018). In controlled feeding experiments, we evaluated the potential of 2 natural algae and 2 alternative (non-marine) diets for the culture of E. marinus and G. locusta. Alternative diets were derived from sus- tainable agriculture and agricultural by-products. Growth performance and survival of the 2 species under different feeding regimes were measured to assess their potential for mass rearing. Resulting gammarid FA profiles were evaluated for their nutritional value as aquafeeds; we also assessed the changes in FA composition in response to different feeding regimes.

\section{MATERIALS AND METHODS}

\subsection{Animal collection and culture}

Gammarus locusta and Echinogammarus marinus (ca. 200 ind. each) were collected in the rocky northern intertidal of the island of Helgoland (German Bight, North Sea) in spring 2018. The animals were then transferred and maintained in laboratory cultures in the facilities of the Alfred Wegener Institute in Bremerhaven. Six collected specimens of each species ( 2 adult males, 2 adult females and 2 juveniles $<1 \mathrm{~cm}$ ) were immediately frozen at $-80^{\circ} \mathrm{C}$ for later FA analysis. All remaining animals were maintained in a recirculating aquaculture system (RAS) with artificial seawater at $15^{\circ} \mathrm{C}$, $30 \mathrm{~g} \mathrm{l}^{-1}$ salinity, $\mathrm{pH}$ 7.8-8 and a light:dark cycle of $12: 12 \mathrm{~h}$

Prior to the experiments, egg-bearing females were isolated from the cultures and kept in separate containers in groups of 5-8 females each of the same species until the juveniles hatched from the females' brood pouches. Within 5 d, juvenile G. locusta were collected from a pool of 10 females, whereas juvenile E. marinus were obtained from a pool of 20 females due to generally smaller brood sizes in the latter species ( 100-120 ind. brood ${ }^{-1}$ female $^{-1}$ in G. locusta, Neuparth et al. 2002, H. Alberts-Hubatsch pers. obs.; and 20-25 ind. in E. marinus, Maranhão \& Marques 2003, pers. obs.). The gathered juveniles were kept in separate containers filled with artificial seawater and segregated by species before they were employed in the experimental setups.

\subsection{Experimental setup}

Four different diet treatments were prepared for the controlled feeding experiment: 2 natural marine food sources, namely thalli of wild-collected green macroalgae (Ulva spp.) and thalli of wild-collected Fucus spp. (hereafter referred to as 'Ulva' and 'Fucus'), and 2 alternative terrestrial food sources, 
i.e. high-protein blue lupin Lupinus angustifolius and low-protein leaves of the domesticated carrot Daucus carota (hereafter referred to as 'lupin' and 'carrot leaves').

The Fucus diet was supplied exclusively to E. marinus, as it is suggested as the (strongly) preferred diet (Martins et al. 2014); all other diets were fed to both G. locusta and E. marinus. The carrot leaves and thalli of Ulva and Fucus were rinsed with fresh water and dried at $50^{\circ} \mathrm{C}$ for $10 \mathrm{~h}$. The lupin diet consisted of lupin meal mixed with water, shaped into pellets and dried at $50^{\circ} \mathrm{C}$ for $16 \mathrm{~h}$.

The experiment was conducted under the same culturing conditions as described above, but containers were detached from the seawater RAS with a $50 \%$ exchange of water every second day using freshly prepared artificial seawater. Experimental containers (Kautex wide-neck square containers, $750 \mathrm{ml}$, brown-transparent) were filled with approximately $500 \mathrm{ml}$ of artificial seawater and equipped with a mesh as substrate $(70 \times 70 \mathrm{~mm}, 5 \mathrm{~mm}$ mesh width). For each species, juveniles were randomly assigned to the respective feeding set-ups, consisting of 5 replicates treatment ${ }^{-1}$ and 30 ind. replicate ${ }^{-1}$. All animals were fed ad libitum, and remaining food items were removed during water exchange and replaced by fresh food; dead individuals were also removed.

The experiment was terminated after $10 \mathrm{wk}$ when the first sexually mature individuals were observed, i.e. when adults formed first mating pairs (precopulae) and egg-bearing females were visible in the trials.

\subsection{Growth and survival}

Initial body lengths of 30 individuals of each amphipod species were measured at the beginning of the experiment. Thereafter, survival and growth were measured after 4 and $8 \mathrm{wk}$ and at the end of experiment (i.e. after $10 \mathrm{wk}$ ). For the growth rates, 10 random specimens from each replicate were taken as subsamples and photographed on scale paper for later analysis. In addition, all remaining animals were weighed individually on an analytical scale (Sartorius Practum 213-S1, d [analytical precision] $=0.001 \mathrm{~g}$ ) to obtain wet weights at the end of the experiment. Initial and intermediate weights were not recorded due to the vulnerability of the juveniles during their early life stages.

For the analysis of growth rates, photographs of the subsamples were analysed using ImageJ (ver. 1.50i;
Schneider et al. 2012). Total lengths were measured from the basal point of the antennae to the third urosome segment.

The specific growth rates (SGR, in $\left.\% \mathrm{~d}^{-1}\right)$ were calculated for each pool as follows:

$$
\begin{aligned}
& \mathrm{SGR}=100 \times[\ln (\text { final length })- \\
& \ln (\text { initial length)/time interval }]
\end{aligned}
$$

Upon completion of the experiment, the sampled specimens were frozen at $-80^{\circ} \mathrm{C}$ prior to freeze drying at $-52^{\circ} \mathrm{C}$ for nutritional analysis.

\subsection{Chemical analysis}

Dried gammarid samples were ground, and $20 \mathrm{mg}$ sub-samples were used for FA analysis. In cases where less than $20 \mathrm{mg}$ of dry sample were obtained (due to mortality), replicates were pooled and $\mathrm{n}$ values adjusted accordingly (see Table 3). The prepared diets were also ground and $150 \mathrm{mg}$ of subsample used for the analysis. Analysis of FA methyl esters (FAMEs) was conducted following Deutsche Gesellschaft für Fettwissenschaft (DGF) standard procedures (DGF standard method C-VI 10a [00]). Lipids were extracted with hexane and incubated overnight. FAs were esterified using sodium ethylate and methanol. FAMEs were analysed using an Agilent 7890 A gas chromatograph (Agilent Technologies) equipped with a flame ionization detector and a Phenomenex Zebron ZB-Fame column (30 m, $0.25 \mathrm{~mm}$ ID, $0.20 \mu \mathrm{m}$ film thickness). FAs (FAMEs) were identified by retention time and comparison with internal standards (FAMEs and PUFAs, both Sigma-Aldrich). Values of FAs (FAMEs) below $0.5 \%$ that had the same value in all samples without variance were considered as residuals or background noise and were excluded from the analysis.

\subsection{Statistical analysis}

Low replicate numbers caused by high mortality in some of the treatments did not allow for growth rate comparison with a repeated-measures ANOVA. Therefore, the measured body lengths were fitted in simple non-linear growth curves with a model selection based on Akaike's information criterion (AIC) where best-fit models were selected by lowest AIC and highest $\mathrm{R}^{2}$ values. Growth curves were then compared with F-tests or chi-squared tests, respectively, depending on the growth model (non-linear or linear/straight line). 
Furthermore, final growth parameters (final length/weight and SGR) for each species were compared between treatments and for all species combined using 1-way ANOVA. Prior to the analysis, data were explored by visual display of residuals and tested for normality (Shapiro-Wilk) as well as homogeneity of variances (Levene's test). For wet weights, normality and homoscedasticity were established by a log-transformation of the data. Survival rates were compared with a non-parametric log-rank test (Mantel-Cox), as the data did not fulfil assumptions for parametric tests.

Principal component analysis (PCA) was used to analyse and visualize the relations between feeds and FA profiles of the 2 species. Additionally, the percentage of similarity (SIMPER) was calculated to determine the FAs responsible for dissimilarities between treatment groups. Permutational multivariate ANOVA (PERMANOVA) was used to test for significant differences between FAs of species and treatment groups. All statistical analyses were performed in PAST 3.16 (Hammer et al. 2001) and GraphPad Prism 5.0. All analyses were performed at a $95 \%$ confidence level.

\section{RESULTS}

\subsection{Growth and survival}

Juvenile Gammarus locusta that had just left the brood pouches measured $1.84 \pm 0.2 \mathrm{~mm}$ (mean \pm $\mathrm{SD})$. The largest final sizes of $G$. locusta $(13.22 \pm 2.15 \mathrm{~mm})$ were obtained in the lupin treatment, followed by carrot-leaf and Ulva treatments (ANOVA, $F_{2,98}=3.969$, $\mathrm{p}=0.022$; Table 1), although only the size difference between the lupin treatment and the Ulva treatment was statistically significant. Similar patterns were observed in the comparison of the different SGRs (ANOVA, $F_{2,98}=$ 4.29, $\mathrm{p}=0.016$ ), with the highest growth rate in the lupin treatment, which was significantly different from the Ulva treatment $(\mathrm{p}=0.011)$. The carrot-leaf treatment did not differ significantly from the other diets $(\mathrm{SGR}=2.39 \pm$ $0.2 \mathrm{~mm}$ ). The analysis of growth models resulted in different regressions for all treatments $\left(F_{8,449}=4.364\right.$, $\mathrm{p}<0.001$ ), with fastest growth in the lupin treatment, followed by carrot-leaf and Ulva (Fig. 1A). Survival rates of $G$. locusta were also statistically different between treatments as presented by survival curves $\left(\chi^{2}=71.97, \mathrm{p}<0.001\right.$; Fig. 1B), with highest survival in the carrot-leaf treatment $(48.7 \%)$, followed by lupin $(14 \%)$ and Ulva $(4.6 \%)$.

Table 1. Growth parameters of Gammarus locusta and Echinogammarus marinus in response to different diets (U: Ulva; F: Fucus; C: carrot leaf, L: lupin meal). Specific growth rate (SGR) shows relative daily growth during the $10 \mathrm{wk}$ feeding trial. $(-)$ All individuals died in this treatment

\begin{tabular}{|c|c|c|c|c|c|c|c|c|c|}
\hline \multirow{2}{*}{$\begin{array}{l}\text { Species/ } \\
\text { diet }\end{array}$} & \multicolumn{2}{|c|}{ Initial size (mm) } & \multicolumn{2}{|c|}{ Final size (mm) } & \multicolumn{2}{|c|}{ Final weight (mg) } & \multirow[t]{2}{*}{ SGR } & \multirow{2}{*}{ SE } & \multirow{2}{*}{$\begin{array}{c}\mathrm{n} \\
\text { (final) }\end{array}$} \\
\hline & Mean & $\mathrm{SD}$ & Mean & $\mathrm{SD}$ & Mean & $\mathrm{SD}$ & & & \\
\hline \multicolumn{10}{|l|}{ G. locusta } \\
\hline $\mathrm{U}$ & 1.84 & 0.2 & 11.41 & 3.28 & 19.57 & 20.11 & 2.30 & 0.13 & 7 \\
\hline $\mathrm{C}$ & 1.84 & 0.2 & 12 & 1.68 & 17.33 & 5.72 & 2.39 & 0.02 & 73 \\
\hline $\mathrm{L}$ & 1.84 & 0.2 & 13.22 & 2.15 & 21.24 & 9.35 & 2.51 & 0.04 & 21 \\
\hline \multicolumn{10}{|c|}{ E. marinus } \\
\hline $\mathrm{F}$ & 2.9 & 0.49 & 7.62 & 1.32 & 5.08 & 2.28 & 1.22 & 0.03 & 55 \\
\hline $\mathrm{C}$ & 2.9 & 0.49 & 5.85 & 0.57 & 2.36 & 1.38 & 0.89 & 0.12 & 7 \\
\hline $\mathrm{L}$ & 2.9 & 0.49 & 6.8 & 0.73 & 3.86 & 1.07 & 1.09 & 0.05 & 7 \\
\hline $\mathrm{U}$ & 2.9 & 0.49 & - & & - & & - & & 0 \\
\hline
\end{tabular}

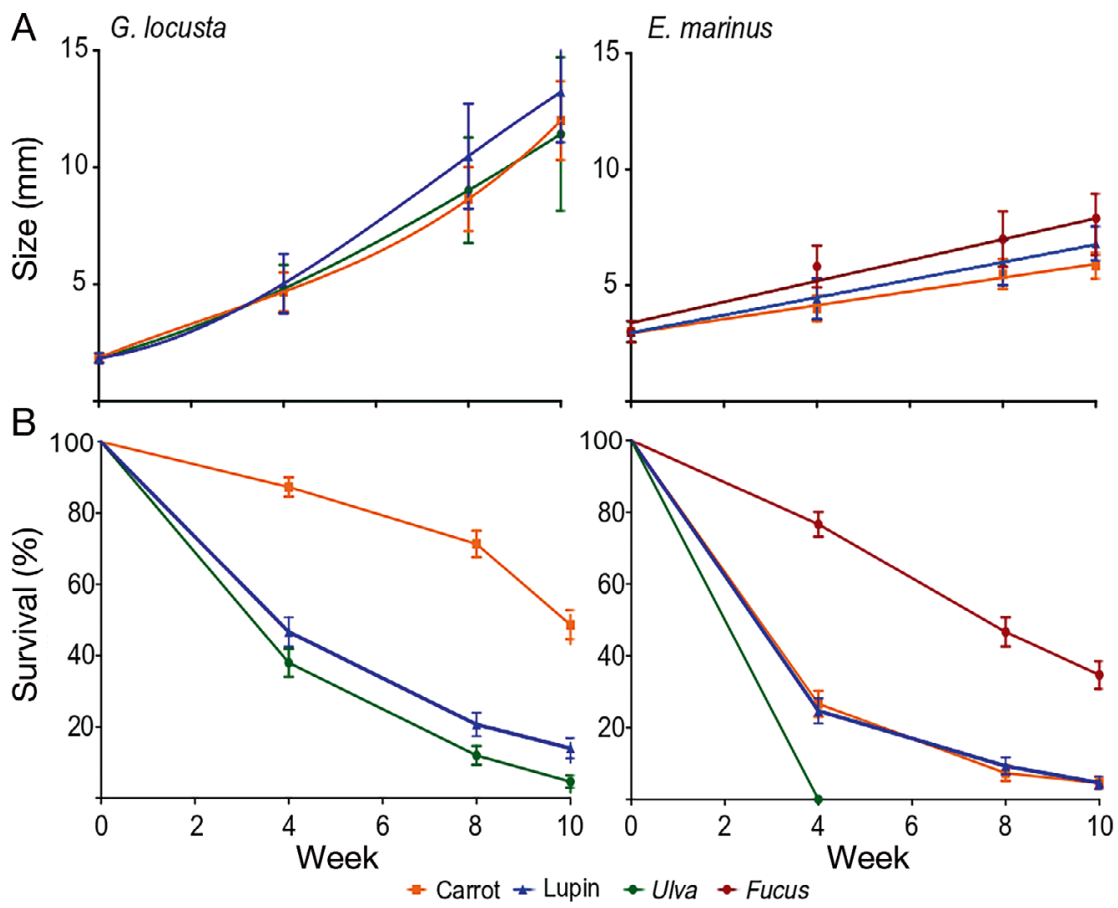

Fig. 1. (A) Growth and (B) survival rates of Gammarus locusta and Echinogammarus marinus raised on different diets 
Juvenile Echinogammarus marinus hatched at significantly larger sizes than G. locusta (ANOVA, $F_{1,68}=150.9$, $\mathrm{p}<0.001)$. However, final sizes and growth rates were lower in all treatments, and no survivors were available in the Ulva treatment (Table 1). Largest final sizes of $E$. marinus were obtained in the Fucus treatment ( 7.62 $\pm 1.32 \mathrm{~mm}$ ), followed by lupin and carrot leaves (Table 1). There were significant differences in sizes between groups $\left(F_{2,66}=7.31 ; \mathrm{p}=0.001\right)$, and pairwise comparisons revealed differences between the carrot leaves and Fucus treatments $(\mathrm{p}<0.001)$, as well as between carrot leaves and lupin ( $\mathrm{p}=0.01)$, but not between lupin and Fucus ( $\mathrm{p}=0.463$ ). The analysis of growth models resulted in different regressions for all treatments $\left(F_{4,341}=\right.$ 24.5, $\mathrm{p}<0.001$; Fig. 1), with fastest growth in the Fucus treatment followed by lupin and carrot leaves (Fig. 1A). The survival curves of $E$. marinus were also significantly different between treatments $\left(\chi^{2}=48.34\right.$, $\mathrm{p}<0.001$; Fig. 1), with highest survival in the Fucus treatment $(34.7 \%)$ and equally low final survival in the carrot leaves and lupin treatments (both $4.6 \%$ ). No animals survived the Ulva treatment at the end of the experiment.

\subsection{FAs}

The FA analysis of the diets revealed high amounts of PUFAs in carrot leaves (73.9\%), followed by Ulva $(50.7 \%)$, lupin $(43.4 \%)$ and Fucus $(39.6 \%)$. In terms of saturated FAs (SFAs), all diets were dominated by palmitic acid (16:0), and Fucus was the only diet containing high levels of myristic acid (14:0, Table 2). Similar to the lupin diet, Fucus had high levels of oleic acid (OA, 18:1-n9), which resulted in high levels of monounsaturated FAs (MUFAs). In terms of PUFAs, the terrestrial diets were both characterized by high amounts of $\gamma$-linolenic acid (GLA, 18:2-n6), while lacking any LC-PUFAs. The carrot-leaf diet was clearly distinguishable from the lupin diet by high amounts of $\alpha$-linolenic acid (ALA, 18:3-n3), also high in the Ulva diet but not in the Fucus diet. LCPUFAs were present in both marine diets; Fucus had
Table 2. Fatty acid (FA) composition ( $\%$ of total FAs) of diets used in the feeding

\begin{tabular}{|c|c|c|c|c|c|c|c|c|}
\hline & \multicolumn{2}{|c|}{ Ulva } & \multicolumn{2}{|c|}{ Fucus } & \multicolumn{2}{|c|}{ Carrot leaf } & \multicolumn{2}{|c|}{ Lupin } \\
\hline & Mean & $\mathrm{SD}$ & Mean & $\mathrm{SD}$ & Mean & $\mathrm{SD}$ & Mean & $\mathrm{SD}$ \\
\hline \multicolumn{9}{|l|}{ Saturated FAs } \\
\hline $14: 0$ & 0.60 & 0.00 & 11.67 & 0.12 & 0.20 & 0.00 & - & - \\
\hline 16:0 (PA) & 31.63 & 1.12 & 14.57 & 0.74 & 18.63 & 1.03 & 12.23 & 0.31 \\
\hline $17: 0$ & - & & 0.93 & 0.49 & 0.23 & 0.06 & & \\
\hline 18:0 & 0.43 & 0.06 & 1.33 & 0.29 & 0.90 & 0.00 & 6.70 & 0.10 \\
\hline 20:0 & - & & 0.57 & 0.15 & 0.23 & 0.06 & 0.40 & 0.26 \\
\hline $22: 0$ & 1.50 & 0.00 & 0.27 & 0.06 & 0.60 & 0.00 & 1.10 & 0.20 \\
\hline 24:0 & - & & 0.30 & 0.00 & 0.80 & 0.10 & 0.17 & 0.12 \\
\hline Total & 34.40 & 0.92 & 30.03 & 0.85 & 21.77 & 1.07 & 20.80 & 0.44 \\
\hline \multicolumn{9}{|c|}{ Monounsaturated FAs } \\
\hline $16: 1$ & 1.07 & 0.06 & 1.57 & 0.12 & 1.73 & 0.15 & - & - \\
\hline $18: 1-n 7$ & 10.90 & 0.17 & 0.37 & 0.12 & 0.20 & 0.00 & 0.73 & 0.06 \\
\hline 18:1-n9 (OA) & 1.37 & 0.06 & 28.00 & 4.37 & 1.60 & 0.10 & 34.90 & 0.36 \\
\hline $22: 1-\mathrm{n} 9$ & 1.43 & 0.06 & - & - & - & - & - & - \\
\hline 22:1-n11 & 0.17 & 0.06 & 0.40 & 0.00 & - & - & - & - \\
\hline Total & 14.90 & 0.00 & 30.33 & 4.15 & 3.67 & 0.15 & 35.80 & 0.44 \\
\hline \multicolumn{9}{|c|}{ Polyunsaturated FAs } \\
\hline 18:2-n6 & 11.80 & 0.00 & 7.00 & 0.26 & 30.03 & 1.62 & 39.20 & 0.17 \\
\hline 18:3-n3 (ALA) & 20.97 & 0.15 & 5.47 & 0.83 & 40.67 & 2.40 & 3.80 & 0.00 \\
\hline $18: 3-\mathrm{n} 6$ & 1.63 & 0.06 & 0.57 & 0.06 & - & - & - & - \\
\hline $18: 4-n 3$ & 9.23 & 0.21 & 3.27 & 0.74 & - & - & - & - \\
\hline 20:3-n3 & 0.97 & 0.32 & - & - & - & - & - & - \\
\hline 20:3-n6 & 0.63 & 0.06 & 0.53 & 0.12 & - & - & - & - \\
\hline 20:4-n6 (ARA) & 2.03 & 0.06 & 14.77 & 0.74 & - & - & - & - \\
\hline 20:5-n3 (EPA) & 0.70 & 0.06 & 7.57 & 1.19 & - & - & - & - \\
\hline 22:5-n3 (DPA) & 2.67 & 0.06 & - & - & - & - & - & - \\
\hline Total & 50.70 & 0.92 & 39.63 & 3.30 & 74.57 & 1.19 & 43.40 & 0.44 \\
\hline \multicolumn{2}{|c|}{ Saturated:unsaturated } & 0.52 & & 0.43 & & 0.28 & & 0.26 \\
\hline
\end{tabular}

highest levels of arachidonic acid (ARA, 20:4-n6) and eicosapentaenoic acid (EPA, 20:5-n3), but lacked any docosapentaenoic acid (DPA, 22:5-n3), which was present in Ulva (Table 2).

PUFA levels of both G. locusta and E. marinus were consistently higher in the treatment groups (57.1$72.54 \%$ ) than in wild-collected specimens (55.67 and $51.67 \%$, respectively). In general, all groups showed low levels of SFAs (12.77-20.67\%), followed by MUFAs (13.62-30.1\%) and PUFAs (57.1-72.5\%). The 2-way PERMANOVA did not show differences in the interaction treatment $\times$ species $(F=-12.12, \mathrm{p}=1)$, but detected significant differences between the species $(F=32.8, \mathrm{p}<0.001)$ as well as among the treatments $(F=49.08, \mathrm{p}<0.001)$. The carrot-leaf treatment of $E$. marinus was excluded from the FA analysis due to high mortality in the experiments, which resulted in insufficient amounts of biomass for the chemical analysis.

PCA revealed a grouping by treatment with $65 \%$ of variance explained by PC1 and $25 \%$ by PC2 (Fig. 2). One group, characterized by high levels of 


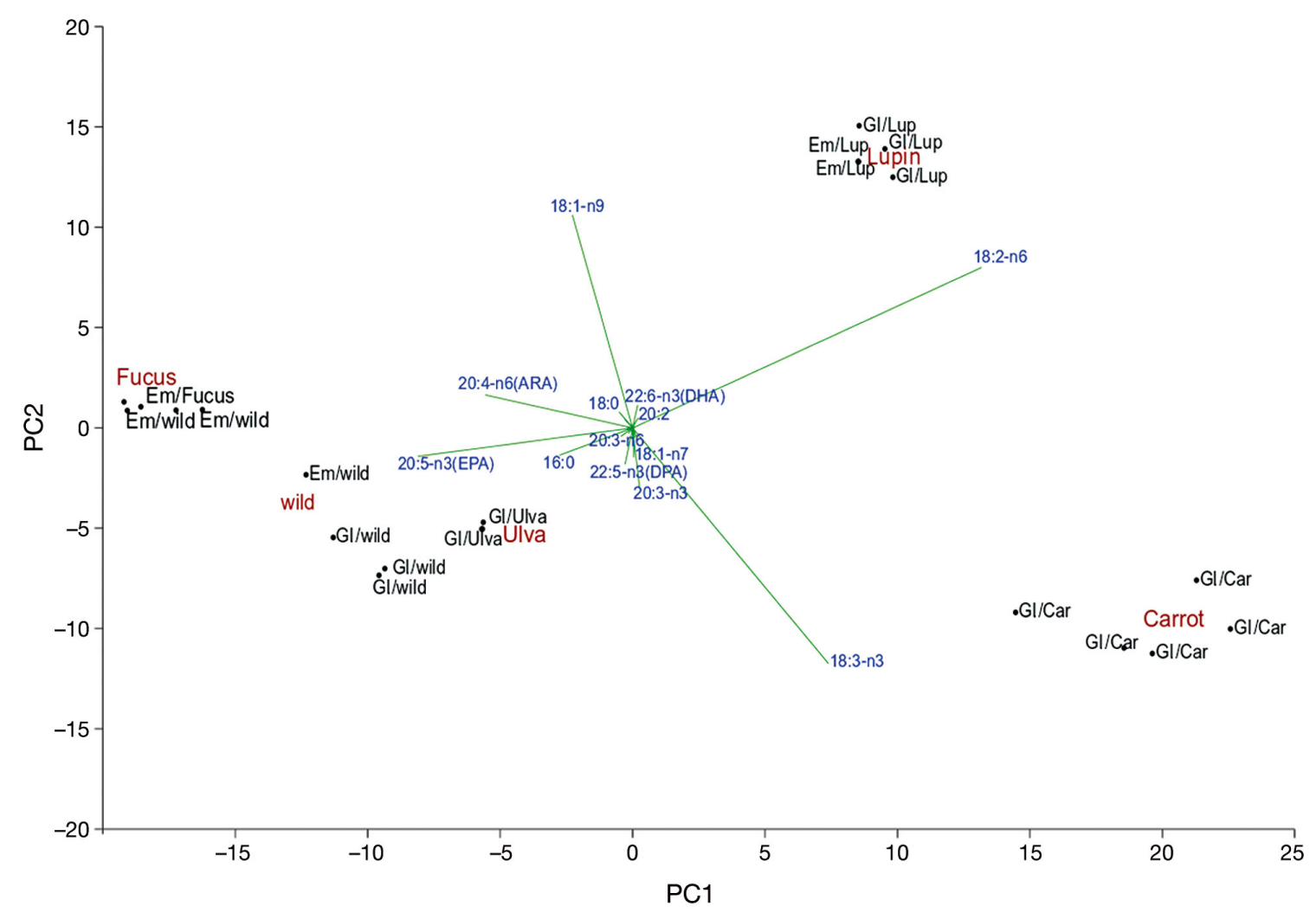

Fig. 2. PCA based on fatty acid composition of Gammarus locusta (Gl) and Echinogammarus marinus (Em) fed different diets (Ulva, Fucus, lupin meal or carrot leaves) and wild-caught individuals. Only major fatty acids responsible for the grouping pattern are displayed in the biplot

EPA, comprised wild-caught specimens as well as both treatment groups. The carrot-leaf group was characterized by high amounts of 18:3-n3 and 18:2n6, of which the latter was shared with the lupin group (Table S1 in the Supplement at www.int-res. com/articles/suppl/q011p481_supp.pdf). The additional SIMPER analysis showed $>40 \%$ dissimilarity with both the algae and the wild group, with 18:2n6 representing $26.24 \%$ of differences with the wildcaught specimens and $18: 3-\mathrm{n} 3$ explaining $21.13 \%$ of difference compared to the algae group (Table S1). The lupin group had the highest amounts of MUFAs and was characterized by high amounts of oleic acid (OA, Table 3, Fig. 2). Furthermore, OA was the main component responsible for the differences to the wild-caught group $(36.06 \%)$ and the algae (both Ulva and Fucus) group (29.92\%, Table S1). In direct comparison with the carrot-leaf group, the lupin group yielded only little amounts of ALA (18:2-n3), and the SIMPER analysis attributed $34.88 \%$ of difference to this FA (Table S1).

FA profiles of wild-caught G. locusta and E. marinus did not differ significantly (PERMANOVA; $F=11.78$, $\mathrm{p}=1.04$ ), both having $>50 \%$ PUFAs, followed by MUFAs and SFAs. Although differences were detected between the treatments for E. marinus (PERMANOVA $_{i} F=49.54, \mathrm{p}=0.003$ ), there were no statistically significant differences in the pairwise comparison. Similar results were observed for the G. locusta groups (PERMANOVA; $F=74.5, \mathrm{p}<0.001$, Table S2), but with significant differences of the carrot-leaf treatment compared to all other treatments including the wild-caught specimens (Table S2). In general, the carrot-leaf treatment of $G$. locusta had the highest amounts of PUFAs $(72.54 \%)$ and the highest n3:n6 ratio of the treatment groups, both of which can be attributed to the high amounts of ALA.

\section{DISCUSSION}

Higher marine invertebrates, such as amphipods, may be viable and sustainable sources of aquaculture diets high in essential nutritional components such as essential FAs. However, the viability of artificial production using formulated diets and the nutri- 
Table 3. Relative composition (\% of total fatty acids, FAs) of Echinogammarus marinus and Gammarus locusta fed different diets after a $10 \mathrm{wk}$ feeding trial. DHA: docosahexaenoic acid, GLA: $\gamma$-linolenic acid; other abbreviations as in Table $2 .{ }^{*}$ indicates pooled samples

\begin{tabular}{|c|c|c|c|c|c|c|c|c|c|c|c|c|}
\hline & \multirow{2}{*}{\multicolumn{4}{|c|}{$\begin{array}{ll} & \text { E. marinus } \\
\text { Wild }(\mathrm{n}=3) & \text { Fucus }\left(\mathrm{n}=3^{*}\right)\end{array}$}} & \multirow{3}{*}{$\begin{array}{l}\text { Lupin } \\
\left(\mathrm{n}=1^{*}\right)\end{array}$} & \multirow{2}{*}{\multicolumn{2}{|c|}{ Wild $(\mathrm{n}=3)$}} & \multirow{3}{*}{$\begin{array}{c}\text { Ulva } \\
\left(\mathrm{n}=1^{*}\right)\end{array}$} & \multirow{2}{*}{\multicolumn{2}{|c|}{$\begin{array}{l}\text { G. locusta } \\
\text { Carrot-leaf }(\mathrm{n}=5)\end{array}$}} & \multirow{2}{*}{\multicolumn{2}{|c|}{ Lupin $(\mathrm{n}=3)$}} \\
\hline & & & & & & & & & & & & \\
\hline & Mean & $\mathrm{SD}$ & Mean & SD & & Mean & $\mathrm{SD}$ & & Mean & SD & Mean & SD \\
\hline \multicolumn{13}{|l|}{ Saturated FAs } \\
\hline $14: 0$ & 0.83 & 0.06 & 0.70 & 0.00 & 0.30 & 0.50 & 0.00 & 0.30 & 0.30 & 0.07 & 0.33 & 0.06 \\
\hline $15: 0$ & 0.37 & 0.06 & 0.30 & 0.00 & 0.40 & 0.50 & 0.00 & 0.60 & 0.42 & 0.08 & 0.47 & 0.06 \\
\hline 16:0 (PA) & 16.67 & 0.49 & 16.50 & 0.10 & 13.40 & 17.57 & 0.15 & 13.20 & 11.82 & 1.13 & 10.00 & 0.70 \\
\hline $17: 0$ & 0.30 & 0.00 & 0.23 & 0.06 & 0.30 & 0.50 & 0.00 & 0.40 & 0.38 & 0.05 & 0.30 & 0.00 \\
\hline $18: 0$ & 2.60 & 0.00 & 2.87 & 0.12 & 3.30 & 2.07 & 0.06 & 2.10 & 1.24 & 0.11 & 1.77 & 0.12 \\
\hline $22: 0$ & 0.57 & 0.12 & 0.13 & 0.06 & 0.30 & 0.90 & 0.00 & 1.30 & 0.30 & 0.07 & 0.30 & 0.00 \\
\hline Total & 21.33 & 0.46 & 20.67 & 0.15 & 17.10 & 22.03 & 0.12 & 17.60 & 13.82 & 1.30 & 12.77 & 0.59 \\
\hline \multicolumn{13}{|c|}{ Monounsaturated FAs } \\
\hline $16: 1$ & 1.17 & 0.15 & 0.37 & 0.06 & 0.70 & 2.00 & 0.17 & 1.50 & 1.42 & 0.19 & 1.47 & 0.21 \\
\hline 18:1-n7 & 2.27 & 0.16 & 0.57 & 0.06 & 0.90 & 4.20 & 0.10 & 4.60 & 2.68 & 0.20 & 2.47 & 0.12 \\
\hline 18:1-n9 (OA) & 22.13 & 0.31 & 18.63 & 0.32 & 22.10 & 15.37 & 0.42 & 11.70 & 9.38 & 0.38 & 25.33 & 3.07 \\
\hline 20:1-n9 & 1.37 & 0.60 & 1.20 & 0.00 & 0.90 & 0.60 & 0.00 & 0.30 & 0.34 & 0.05 & 0.87 & 0.15 \\
\hline Total & 27.00 & 0.35 & 20.83 & 0.21 & 24.60 & 22.17 & 0.68 & 17.80 & 13.62 & 0.57 & 30.13 & 3.40 \\
\hline \multicolumn{13}{|l|}{ Polyunsaturated FAs } \\
\hline 18:2-n6 (GLA) & 4.37 & 0.40 & 5.17 & 0.15 & 29.80 & 6.07 & 0.06 & 12.00 & 26.58 & 2.58 & 28.60 & 0.89 \\
\hline 18:3-n3 (ALA) & 2.80 & 0.26 & 1.57 & 0.06 & 2.20 & 6.77 & 0.06 & 8.60 & 23.10 & 1.81 & 3.77 & 0.67 \\
\hline 18:3-n6 & 0.10 & 0.00 & 0.10 & 0.00 & 0.30 & 0.20 & 0.00 & 0.40 & 0.30 & 0.07 & 0.30 & 0.00 \\
\hline $18: 4-n 3$ & 0.93 & 0.11 & 0.63 & 0.11 & 0.30 & 1.97 & 0.06 & 1.00 & 0.30 & 0.07 & 0.30 & 0.00 \\
\hline $20: 2$ & 1.47 & 0.15 & 1.87 & 0.03 & 2.60 & 0.60 & 0.00 & 0.80 & 1.64 & 0.15 & 1.10 & 0.10 \\
\hline $20: 3-n 3$ & 1.33 & 0.15 & 0.67 & 0.06 & 0.30 & 5.00 & 3.47 & 0.40 & 4.38 & 0.75 & 1.17 & 0.25 \\
\hline 20:3-n6 & 0.60 & 0.00 & 0.40 & 0.00 & 0.30 & 0.67 & 0.06 & 1.20 & 0.88 & 1.24 & 0.30 & 0.00 \\
\hline 20:4-n6 (ARA) & 9.30 & 0.26 & 22.17 & 0.32 & 5.80 & 2.97 & 3.32 & 14.90 & 3.68 & 2.01 & 7.17 & 0.90 \\
\hline 20:5-n3 (EPA) & 19.70 & 0.60 & 20.30 & 0.30 & 10.00 & 20.30 & 0.36 & 15.80 & 5.10 & 1.81 & 7.13 & 0.96 \\
\hline 22:5-n3 (DPA) & 2.13 & 0.12 & 1.17 & 0.11 & 0.30 & 2.63 & 0.06 & 3.20 & 2.20 & 0.76 & 0.40 & 0.17 \\
\hline 22:6-n3 (DHA) & 5.03 & 0.06 & 4.57 & 0.49 & 7.60 & 8.50 & 0.26 & 6.30 & 5.28 & 2.02 & 7.87 & 1.75 \\
\hline Total & 51.67 & 0.42 & 58.50 & 0.10 & 58.30 & 55.67 & 0.72 & 64.60 & 72.54 & 1.79 & 57.10 & 3.99 \\
\hline Total n-3 & 35.93 & & 28.90 & & 20.70 & 45.17 & & 35.30 & 40.36 & & 20.63 & \\
\hline Total n-6 & 14.37 & & 27.83 & & 36.20 & 9.90 & & 28.50 & 31.44 & & 36.37 & \\
\hline Ratio n-3:n6 & 2.50 & & 1.04 & & 0.57 & 4.56 & & 1.24 & 1.28 & & 0.57 & \\
\hline DHA:EPA & 0.26 & & 0.22 & & 0.76 & 0.42 & & 0.40 & 1.04 & & 1.10 & \\
\hline DHA:ARA & 0.54 & & 0.21 & & 1.31 & 2.87 & & 0.42 & 1.43 & & 1.10 & \\
\hline EPA:ARA & 2.12 & & 0.92 & & 1.72 & 6.84 & & 1.06 & 1.39 & & 1.00 & \\
\hline Saturated:unsaturated & 0.27 & & 0.26 & & 0.21 & 0.28 & & 0.21 & 0.16 & & 0.18 & \\
\hline
\end{tabular}

tional quality of the resulting amphipods have remained uninvestigated until now. The current study demonstrates that marine amphipods can be reared exclusively with sustainable formulated diets and exhibit adequate FA profiles needed for applications as aquaculture diets.

\subsection{Growth and survival}

Juveniles of the 2 gammarid amphipods Gammarus locusta and Echinogammarus marinus survived and grew to sexual maturity when fed terrestrial diets in cn RAS but were characterized by differences in growth and survival responses to various diets. In di- rect comparisons, G. locusta showed distinctly better growth and survival rates on all tested diets in our experiments. G. locusta is known for its opportunistic life strategy, being able to cope with changing environments and variations in food supply (Costa \& Costa 2000). It naturally occurs in different habitats, from shallow intertidal areas to subtidal algae beds, and can often be found associated with nektonic drift algae (Fincham 1970, Tully \& Céidigh 1986, Gutow et al. 2015). These different habitats generate different food availability, resulting in a distinctively opportunistic feeding strategy of $G$. locusta that may even include terrestrial food items.

In contrast, E. marinus, which achieved very poor survival rates for any diet other than the natural 
Fucus diet, exhibits a more specialised life strategy and is strongly restricted to intertidal Fucus habitats. Even though this species can express predatory behaviour (Dick et al. 2005, Alexander et al. 2013), it shows strong preferences for Fucus spp. in its herbivorous diet (Martins et al. 2014). Life in harsh intertidal habitats may also be corroborated by a prolonged brood care strategy, which is indicated by much higher sizes at hatching. It remains unclear whether the diet preparation as formulated diets, including drying, reduced the palatability of otherwise wet and whole natural diets such as Fucus and Ulva. In the current study, however, all diets were readily consumed, and the highest rates of survival and growth were observed for E. marinus with dried Fucus and for G. locusta with dried carrot leaves.

The high survival of $G$. locusta when fed carrot leaves might be partially explained by high levels of carotenoids in carrot leaves, which can be higher than $700 \mathrm{mg}$ per $100 \mathrm{~g}$ of dry weight (Booth 1957, Perrin et al. 2016). Specimens of this treatment group featured more intense pigmentation and had a dark orange colouration after freezedrying (Fig. S1). In contrast, specimens raised on the lupin treatment were almost achromatic. This observation has also been confirmed for other crustaceans that were fed with diets poor in pigments (Howell \& Matthews 1991). In addition to enhanced pigmentation in crustaceans, health-promoting effects such as anti-inflammatory and antioxidative effects and photo-protection have also been attributed to carotenoids (e.g. Liñán-Cabello et al. 2002).

The low survival rates of E. marinus and $G$. locusta in the lupin diet treatment must be regarded with caution, as the rapid decay of the lupin flour may have occasionally led to a decrease in water quality. However, parametric measurements of water were not made in the current study due to the frequent water exchanges in the experimental containers. Lupin, like many other plant diet ingredients, and in particular legumes, can exhibit strong anti-nutritive or allergenic effects on invertebrates, including key aquaculture species (Francis et al. 2001, Dersjant-Li 2002). While these are poorly understood in invertebrates to date, any inclusion of lupin may require pre-treatments or appropriate dose limitations if antinutritive effects are found. Generally, the feasibility of lupin as a diet for culturing gammarids cannot be excluded, especially as G. locusta also exhibited good growth rates in this treatment.

\subsection{FA profiles}

The analysis of FAs revealed high ratios of PUFAs in both wild-caught specimens and experimental treatment groups for both species. The FA composition of all treatment groups was characterized by elevated PUFA and LC-PUFA levels and decreased levels of SFA und MUFA compared to wild-caught specimens. This pattern was observed when the amphipods were fed algae as their natural marine diet, but also when they were fed terrestrial diets consisting of carrot leaves and lupin, which lack any LC-PUFAs. This is the first evidence that gammarid crustaceans have broad capacities to convert $\mathrm{C}_{18^{-}}$ PUFAs to $\geq \mathrm{C}_{20}$-PUFAs. This 'trophic upgrading' is well known from many freshwater and diadromous fish species, but not from marine fish (Monroig et al. 2013), and limited capabilities are known from marine invertebrates such as shrimp (D'Abramo 1997) and polychaetes (Olive et al. 2009). However, whether gammarids are able to synthesize PUFAs completely de novo is worthy of further investigation.

Carrot leaves were generally high in both n3- and n6-FAs of the $\mathrm{C}_{18}$-group. Consequently, gammarids in this treatment showed high amounts of these FAs along with high levels of LC-PUFAs. Even though the carrot-leaf fed group had lower amounts of LC-PUFAs compared to Ulva and lupin diets, the DHA:EPA:ARA ratio of the carrot-fed gammarids was the only one that met the recommended availability (DHA $>$ EPA $>$ ARA) needed for the healthy development of marine fish (Glencross 2009, Tocher 2010, Hamre et al. 2013). In addition to LC-PUFAs, the carrot-fed gammarids exhibited high levels of ALA (18:2-n6) and GLA (18:3$\mathrm{n} 3)$, which would meet the nutritional demands of many freshwater fish and some marine crustaceans, in which these are considered essential (Sargent et al. 1997, Glencross 2009). In marine environments, for example, shrimps need ALA and GLA as essential FAs, with LC-PUFAs considered beneficial but not essential (Kanazawa et al. 1979). In contrast, other crustaceans (e.g. the portunid crab Scylla serrata) still depend on LC-PUFAs for healthy development (Suprayudi et al. 2004). Consequently, the definition of 'essentiality' of FAs in crustaceans seems to be taxon-specific and should be investigated as such.

E. marinus showed high levels of ARA and EPA throughout the treatments, questioning its suitability for aquaculture feeds that normally require high levels of DHA (Izquierdo \& Fernandez-Palacios 1997, Sargent et al. 1999, Williams 2007, Glencross 2009, Hamre et al. 2013). Levels of ARA and EPA exceeding those of DHA can lead to growth deficiencies 
(e.g. malpigmentation) in fish larvae, but exact optimal levels and ratios need to be investigated for each fish species individually (Hamre et al. 2013). Thus, the high levels of ARA and EPA in E. marinus might be suitable as an additive in dry feeds, but not as live feed.

\subsection{Implications for sustainable aquaculture}

In the last decade, the use of amphipod meal as a substitute for fishmeal has become increasingly important. In Norway, meal of wild-caught pelagic amphipods (Themisto libellula) was used as a full substitute in formulated cod and salmon feeds and showed similar or even improved growth rates compared with fishmeal diets (Moren et al. 2006). Several amphipod species have been tested as live/wholeanimal diets for their suitability in rearing hatchlings of the cuttlefish Sepia officinalis, with good growth rates when fed gammarids, but poor growth when the diet consisted of caprellid amphipods (BaezaRojano et al. 2010). Furthermore, paralarvae of the octopus Robsonella fontaniana exhibited good development during the first 3 mo when fed with the fouling amphipod Jassa marmorata (González et al. 2011). In comparison to the freshwater gammarid Hyalella azteca or Artemia sp., the marine gammarid Hyale media promoted better growth in hatchlings of Octopus maya (Baeza-Rojano et al. 2013), which might be attributable to the better nutritional profile, especially in FAs, of marine gammarid species (Baeza-Rojano et al. 2013, 2014). Growth rates in amberjack Seriola dumerili fry were higher when fed commercial feeds compared to Gammarus insensibilis lyophilizate; however, survival rates were far higher when fed the gammarid, with morphometry and colour pattern resembling wild-caught fry (Jiménez-Prada 2018). Changes in behaviour were also observed; amberjack fed gammarids displayed less aggressive behaviour during feeding (JiménezPrada 2018). In direct comparison to our findings, the FA ratios of $G$. insensibilis in that study were even weaker in terms of PUFAs. This indicates an even greater potential for the use of G. locusta as feedstuff in aquaculture applications. Given the high nutritional value of amphipods, concepts of integrating caprelllid amphipods into fish-culturing systems have been formulated (Guerra-García et al. 2016), and harvesting systems for marine amphipods at offshore aquaculture systems have been employed (Fernandez-Gonzalez et al. 2018), both supporting sustainable fish-culturing concepts.
The gammarids tested represent a novel biological vector to valorise agricultural green waste, adding to existing direct bioactive extraction (e.g. Tuck et al. 2012, Putnik et al. 2017) or widely applied energetic valorisation (Münster \& Meibom 2011). In the current study, carrot-leaf valorisation showed a strong potential to reduce agriculture waste streams and increase aquaculture efficiency. While carrot leaves do not represent the largest agriculture waste stream, results also point toward the potential to test feeding of other green waste streams and/or nuisance algae to produce high-value FAs for sustainable aquaculture purposes.

In summary, marine gammarids bio-convert shorterchain FAs to LC-PUFAs (i.e. trophic upgrading) from agriculture waste and non-marine diets for healthy growth in culture. Combining growth performance and survival with the results from the FA profiling indicates high suitability of $G$. locusta as a future aquaculture diet source. E. marinus, in comparison, provides beneficial FA profiles for aquatic animal nutrition, but poor growth performance makes it unfit for applications as an aquaculture species. Nevertheless, this could be a reflection of the culture conditions and feeds used in the current experiment, which may be adjusted to improve their suitability for commercial aquaculture production.

In general, FA profiles of G. locusta have adequate nutritional value for applications in aquaculture, but the suitability for different fish or crustacean species remains to be investigated in a species-dependent manner. By manipulating FA profiles of G. locusta with selected feeds, we can adjust the gammarid to requirements in terms of general dietary FA contents as well as ARA, EPA and DHA of the target species and produce a designer feed using sustainable processes. By using residues from land-based production for the culture of organisms used for feeding in aquaculture, we could add new opportunities to a circular green economy.

Acknowledgements. We thank the technical staff at the Centre for Aquaculture Research (ZAF) at the Alfred Wegener Institute, Helmholtz Centre for Polar and Marine Research (AWI), for steady support during the experiments. Allison Hall-Mullen and Juliane Schötz assisted during the animal collections. This research was made possible by the AWI Innovation Fund and the Helmholtz Association.

\section{LITERATURE CITED}

Alexander ME, Dick JTA, O'Connor NE (2013) Born to kill: predatory functional responses of the littoral amphipod Echinogammarus marinus Leach throughout its life history. J Exp Mar Biol Ecol 439:92-99 
Amara R, Laffargue P, Dewarumez JM, Maryniak C, Lagardère $F$, Luczac $C$ (2001) Feeding ecology and growth of O-group flatfish (sole, dab and plaice) on a nursery ground (Southern Bight of the North Sea). J Fish Biol 58: 788-803

Baeza-Rojano E, García S, Garrido D, Guerra-García JM, Domingues P (2010) Use of amphipods as alternative prey to culture cuttlefish (Sepia officinalis) hatchlings. Aquaculture 300:243-246

Baeza-Rojano E, Domingues P, Guerra-García JM, Capella S, Noreña-Barroso E, Caamal-Monsreal C, Rosas C (2013) Marine gammarids (Crustacea: Amphipoda): a new live prey to culture Octopus maya hatchlings. Aquacult Res 44:1602-1612

Baeza-Rojano E, Hachero-Cruzado I, Guerra-García JM (2014) Nutritional analysis of freshwater and marine amphipods from the Strait of Gibraltar and potential aquaculture applications. J Sea Res 85:29-36

Barlow CG, Allan GL, Williams KC, Rowland SJ, Smith DM (2003) Aquaculture diet development subprogram: diet validation and feeding strategies. NSW Fisheries FRDC, Cronulla

Beermann J, Boos K, Gutow L, Boersma M, Peralta AC (2018) Combined effects of predator cues and competition define habitat choice and food consumption of amphipod mesograzers. Oecologia 186:645-654

Booth BVH (1957) Carotene in the leaves of the carrot. J Sci Food Agric 8:371-376

Brett MT, Muller-Navarra DC (1997) The role of highly unsaturated fatty acids in aquatic food web processes. Freshw Biol 38:483-499

Costa FO, Costa MH (2000) Review of the ecology of Gammarus locusta (L.). Pol Arch Hydrobiol 47:541-559

D'Abramo LR (1997) Triacylglycerols and fatty acids. In: D'Abramo LR, Conklin DE, Akiyama DM (eds) Crustacean nutrition. Advances in world aquaculture Vol 6. World Aquaculture Society, Baton Rouge, LA, p 71-84

Nauby P, Scailteur Y, De Broyer C (2001) Trophic diversity within the Eastern Weddell Sea amphipod community. Hydrobiologia 443:69-86

Dersjant-Li Y (2002) The use of soy protein in aquafeeds. In: Cruz-Suárez LE, Ricque-Marie D, Tapia-Salazar M, Gaxiola-Cortés MG, Simoes N (eds) Advaces en nutricion acuicola VI. Memorias del VI Simposium Internacional de Nutrcion Acuicola, 3 al 6 de Septiembre del 2002, Cancún, Quintana Roo, México, p 541-558

* Dick JTA, Johnson MP, McCambridge S, Johnson J, Carson VEE, Kelly DW, MacNeil C (2005) Predatory nature of the littoral amphipod Echinogammarus marinus: gut content analysis and effects of alternative food and substrate heterogeneity. Mar Ecol Prog Ser 291:151-158

Edgar GJ (1990) Predator-prey interactions in seagrass beds. II. Distribution and diet of the blue manna crab Portunus pelagicus Linnaeus at Cliff Head, Western Australia. J Exp Mar Biol Ecol 139:23-32

FAO (2018) The state of world fisheries and aquaculture 2018- meeting the sustainable development goals. FAO, Rome

Fernandez-Gonzalez V, Toledo-Guedes K, Valero-Rodriguez JM, Agraso MM, Sanchez-Jerez P (2018) Harvesting amphipods applying the integrated multitrophic aquaculture (IMTA) concept in off-shore areas. Aquaculture 489:62-69

Fincham AA (1970) Amphipods in the surf plankton. J Mar Biol Assoc UK 50:177-198
Floreto EAT, Bayer RC, Brown PB (2000) The effects of soybean-based diets, with and without amino acid supplementation, on growth and biochemical composition of juvenile American lobster, Homarus americanus. Aquaculture 189:211-235

Francis G, Makkar HPS, Becker K (2001) Antinutritional factors present in plant-derived alternate fish feed ingredients and their effects in fish. Aquaculture 199:197-227

Glencross BD (2009) Exploring the nutritional demand for essential fatty acids by aquaculture species. Rev Aquacult 1:71-124

*González ML, Pérez-Schultheiss J, López DA (2011) Exotic amphipods in aquaculture systems: presence and potential use. Crustaceana 84:769-775

Guerra-García JM, Hachero-Cruzado I, González-Romero P, Jiménez-Prada P, Cassell C, Ros M (2016) Towards integrated multi-trophic aquaculture: lessons from caprellids (Crustacea: Amphipoda). PLOS ONE 11:e0154776

Gutow L, Beermann J, Buschbaum CM, Rivadeneira M, Thiel M (2015) Castaways can't be choosers-homogenization of rafting assemblages on floating seaweeds. J Sea Res 95:161-171

Hammer Ø, Harper DAT, Ryan PD (2001) PAST: Paleontological statistics software package for education and data analysis. Palaeontol Electron 4:art4

*Hamre K, Yúfera M, Rønnestad I, Boglione C, Conceição LEC, Izquierdo M (2013) Fish larval nutrition and feed formulation: knowledge gaps and bottlenecks for advances in larval rearing. Rev Aquacult 5:S26-S58

Howell BK, Matthews AD (1991) The carotenoids of wild and blue disease affected farmed tiger shrimp (Penaeus monodon, Fabricus [sic]). Comp Biochem Physiol 98B: 375-379

*Hughes LE, Ahyong ST (2016) Collecting and processing amphipods. J Crustac Biol 36:584-588

Izquierdo M, Fernandez-Palacios H (1997) Nutritional requirements of marine fish larvae and broodstock. CIHEAM Options Mediterr 264:243-264

Jiménez-Prada P (2018) Use of amphipods (Crustacea: Peracarida: Amphipoda) in aquaculture. PhD thesis, Universidad de Sevilla

Jiménez-Prada P, Hachero-Cruzado I, Giráldez I, Fernández-Diaz C, Vilas C, Cañavate JP, Guerra-García JM (2018) Crustacean amphipods from marsh ponds: a nutritious feed resource with potential for application in integrated multi-trophic aquaculture. PeerJ 6:e4194

Kabeya N, Fonseca MM, Ferrier DEK, Navarro JC and others (2018) Genes for de novo biosynthesis of omega-3 polyunsaturated fatty acids are widespread in animals. Sci Adv 4:eaar6849

Kanazawa A, Teshima S, Tokiwa S, Ceccaldi HJ (1979) Essential fatty acids in prawn. I. Effect of linoleic and linolenic acids on growth. Oceanol Acta 2:1111-1114

Khodadadnia M, Karimzadeh K, Zahmatkesh A (2016) Total lipid, fatty acid composition and lipid peroxidation of Pontogammarus maeoticus (Crustacea, Amphipoda, Pontogammaridae) in Caspian Sea, Iran. Aquacult Aquarium Conserv Legis 9:985-992

*Lagardère F (1987) Feeding ecology and daily food consumption of common sole, Solea vulgaris Quensel, juveniles on the French Atlantic coast. J Fish Biol 30:91-104

Li án-Cabello MA, Paniagua-Michel J, Hopkins PM (2002) Bioactive roles of carotenoids and retinoids in crustaceans. Aquacult Nutr 8:299-309

Maranhão P, Marques JC (2003) The influence of tempera- 
ture and salinity on the duration of embryonic development, fecundity and growth of the amphipod Echinogammarus marinus Leach (Gammaridae). Acta Oecol 24: 5-13

Martins I, Leite N, Constantino E (2014) Consumption and feeding preference of Echinogammarus marinus on two different algae: Fucus vesiculosus and Ulva intestinalis. J Sea Res 85:443-446

Monroig Ó, Tocher DR, Navarro JC (2013) Biosynthesis of polyunsaturated fatty acids in marine invertebrates: recent advances in molecular mechanisms. Mar Drugs 11:3998-4018

Moren M, Suontama J, Hemre GI, Karlsen O, Olsen RE, Mundheim H, Julshamn K (2006) Element concentrations in meals from krill and amphipods - possible alternative protein sources in complete diets for farmed fish. Aquaculture 261:174-181

Münster M, Meibom P (2011) Optimization of use of waste in the future energy system. Energy 36:1612-1622

Naylor RL, Hardy RW, Bureau DP, Chiu A and others (2009) Feeding aquaculture in an era of finite resources. Proc Natl Acad Sci USA 106:15103-15110

Neuparth T, Costa FO, Costa MH (2002) Effects of temperature and salinity on life history of the marine amphipod Gammarus locusta. Implications for ecotoxicological testing. Ecotoxicology 11:61-73

Nichols PD, Petrie J, Singh S (2010) Long-chain omega-3 oils - an update on sustainable sources. Nutrients 2: $572-585$

Odum WE, Heald EJ (1972) Trophic analyses of an estuarine mangrove community. Bull Mar Sci 22:671-738

* Olive PJW, Duangchinda T, Ashforth E, Craig S, Ward AC, Davies SJ (2009) Net gain of long-chain polyunsaturated fatty acids (PUFA) in a lugworm Arenicola marina bioturbated mesocosm. Mar Ecol Prog Ser 387:223-239

Parrish CC (2009) Essential fatty acids in aquatic food webs. In: Arts MT, Brett MT, Kainz MJ (eds) Lipids in aquatic ecosystems. Springer, Dordrecht, p 309-326

Perrin F, Brahem M, Dubois-Laurent C, Huet S and others (2016) Differential pigment accumulation in carrot leaves and roots during two growing periods. J Agric Food Chem 64:906-912

Pita C, Gamito S, Erzini K (2002) Feeding habits of the gilthead seabream (Sparus aurata) from the Ria Formosa (southern Portugal) as compared to the black seabream (Spondyliosoma cantharus). J Appl Ichthyol 18:81-86

Editorial responsibility: Pablo Sánchez Jerez, Alicante, Spain
Putnik P, Bursać Kovačević D, Režek Jambrak A, Barba FJ and others (2017) Innovative 'green' and novel strategies for the extraction of bioactive added value compounds from citrus wastes - a review. Molecules 22:680

Sargent JR, McEvoy LA, Bell JG (1997) Requirements, presentation and sources of polyunsaturated fatty acids in marine fish larval feeds. Aquaculture 155:117-127

Sargent J, Bell G, McEvoy L, Tocher D, Estevez A (1999) Recent development in the essential fatty acid nutrition of fish. Aquaculture 177:191-199

Schneider CA, Rasband WS, Eliceiri KW (2012) NIH Image to ImageJ: 25 years of image analysis. Nat Methods 9: 671-675

Sexton EW (1928) On the rearing and breeding of Gammarus in laboratory conditions. J Mar Biol Assoc UK 15:33-55

* Suprayudi MA, Takeuchi T, Hamasaki K (2004) Essential fatty acids for larval mud crab Scylla serrata: implications of lack of the ability to bioconvert C18 unsaturated fatty acids to highly unsaturated fatty acids. Aquaculture 231: 403-416

Tempestini A, Rysgaard S, Dufresne F (2018) Species identification and connectivity of marine amphipods in Canada's three oceans. PLOS ONE 13:e0197174

Tocher DR (2010) Fatty acid requirements in ontogeny of marine and freshwater fish. Aquacult Res 41:717-732

Tuck CO, Pérez E, Horváth IT, Sheldon RA, Poliakoff M (2012) Valorization of biomass: deriving more value from waste. Science 337:695-699

* Tully O, Céidigh PÓ (1986) The ecology of Idotea species (Isopoda) and Gammarus locusta (Amphipoda) on surface driftweed in Galway Bay (West Ireland). J Mar Biol Assoc UK 66:931-942

₹Väinölä R, Witt JDS, Grabowski M, Bradbury JH, Jazdzewski K, Sket B (2008) Global diversity of amphipods (Amphipoda; Crustacea) in freshwater. Hydrobiologia 595:241-255

Wakabara Y, Kawakami de Rezende E, Tararam AS (1982) Amphipods as one of the main food components of three Pleuronectiformes from the continental shelf of South Brazil and North Uruguay. Mar Biol 68:67-70

Williams KC (2007) Nutritional requirements and feeds development for post-larval spiny lobster: a review. Aquaculture 263:1-14

*Woods CMC (2009) Caprellid amphipods: an overlooked marine finfish aquaculture resource? Aquaculture 289: $199-211$

Submitted: March 29, 2019; Accepted: July 25, 2019

Proofs received from author(s): September 5, 2019 